\title{
Variables associated with health-related quality of life in a Brazilian sample of patients from a tertiary outpatient clinic for depression and anxiety disorders
}

\author{
Variáveis associadas à qualidade de vida em uma amostra de pacientes de um \\ serviço ambulatorial terciário para transtornos de ansiedade e depressão
}

Bianca Schwab, ${ }^{1}$ Heloisa Silveira Daniel, ${ }^{2}$ Carine Lutkemeyer, ${ }^{2}$ João Arthur Lange Lins Neves, ${ }^{3}$ Louise Nassif Zilli, ${ }^{1}$ Ricardo Guarnieri, ${ }^{4}$ Alexandre Paim Diaz, ${ }^{4}$ Ana Maria Maykot Prates Michels ${ }^{5}$

\begin{abstract}
Introduction: Health-related quality of life (HRQOL) assessment tools have been broadly used in the medical context. These tools are used to measure the subjective impact of the disease on patients. The objective of this study was to evaluate the variables associated with HRQOL in a Brazilian sample of patients followed up in a tertiary outpatient clinic for depression and anxiety disorders.

Method: Cross-sectional study. Independent variables were those included in a sociodemographic questionnaire and the Hospital Anxiety and Depression Scale (HADS) scores. Dependent variables were those included in the short version of the World Health Organization Quality of Life (WHOQOL-BREF) and the scores for its subdomains (overall quality of life and general health, physical health, psychological health, social relationships, and environment). A multiple linear regression analysis was used to find the variables independently associated with each outcome. Results: Seventy-five adult patients were evaluated. After multiple linear regression analysis, the HADS scores were associated with all outcomes, except social relationships $(p=0.08)$. Female gender was associated with poor total scores, as well as psychological health and environment. Unemployment was associated with poor physical health.

Conclusion: Identifying the factors associated with HRQOL and recognizing that depression and anxiety are major factors are essential to improve the care of patients.

Keywords: Quality of life, depression, anxiety.
\end{abstract}

\section{Resumo}

Introdução: Instrumentos para avaliar qualidade de vida relacionada à saúde têm sido amplamente utilizados no contexto médico, visando mensurar o impacto da doença de uma perspectiva subjetiva e relevante ao paciente. $O$ objetivo desse estudo foi identificar variáveis associadas à qualidade de vida em uma amostra de pacientes acompanhados em um ambulatório terciário para transtornos de ansiedade e depressão.

Métodos: Estudo transversal. As variáveis independentes incluíram dados de um questionário sociodemográfico e pontuação na Escala Hospitalar de Ansiedade e Depressão (HADS). Variáveis dependentes: pontuação total na escala breve de qualidade de vida da Organização Mundial de Saúde (WHOQOL-Bref) e cada um de seus subdomínios (geral, físico, psicológico, social e ambiental). Regressão linear múltipla foi aplicada para identificar as variáveis preditoras associadas de forma independente a cada uma das variáveis dependentes.

Resultados: Setenta e cinco pacientes adultos foram avaliados. Após análise de regressão linear múltipla, pontuação na HADS esteve associada com todos os desfechos analisados, exceto para o subdomínio social $(p=0,08)$. Sexo feminino esteve negativamente associado com a pontuação total da WHOQOL-Bref e com os subdomínios psicológico e ambiental. Desemprego esteve associado com o subdomínio físico.

Conclusão: $\mathrm{A}$ identificação de fatores associados à qualidade de vida relacionada à saúde e o reconhecimento de que a depressão e a ansiedade são variáveis fundamentais são essenciais para uma melhor assistência aos pacientes.

Descritores: Qualidade de vida, depressão, ansiedade.

\footnotetext{
${ }^{1}$ Medical Residency Program, Instituto de Psiquiatria de Santa Catarina (IPQ/SC), São José, SC, Brazil. ${ }^{2}$ Medical student, Universidade Federal de Santa Catarina (UFSC), Florianópolis, SC, Brazil. ${ }^{3}$ Psychiatrist, Prefeitura de São José, São José, SC, Brazil. ${ }^{4}$ Preceptor, Medical Residency Program, IPQ/SC, São José, SC, Brazil. ${ }^{5}$ Preceptor and coordinator, Medical Residency Program, IPQ/SC, São José, SC, Brazil. Professor of Psychiatry, UFSC, Florianópolis, SC, Brazil. Financial support: none.

Submitted Mar 02 2015, accepted for publication May 07 2015. No conflicts of interest declared concerning the publication of this article.

Suggested citation: Schwab B, Daniel HS, Lutkemeyer C, Neves JA, Zilli LN, Guarnieri R, et al. Variables associated with health-related quality of life in a Brazilian sample of patients from a tertiary outpatient clinic for depression and anxiety disorders. Trends Psychiatry Psychother. 2015;37(4):202-208. http://dx.doi. org/10.1590/2237-6089-2015-0013
} 


\section{Introduction}

Conventional ways of assessing medical outcomes usually consider only specific symptoms of the disease, ignoring the patients' subjective difficulties in their activities of daily living. ${ }^{1}$ In regard to chronic disease, these conventional methods may not be fully effective because the goal of the treatment is not to cure the disease but to reduce its burden on several aspects of the patient's life. ${ }^{2}$

Health-related quality of life (HRQOL) assessment tools have been broadly used in the medical context. These tools are used to measure the subjective impact of the disease on patients and try to identify specific variables associated with its burden. ${ }^{1,3}$ Quality of life measurement has proven useful for both research and clinical practice because it helps evaluate the benefits of therapeutic interventions and compare the outcomes of different treatments. ${ }^{2-4}$

Depression and anxiety disorders are a global health problem, with significant prevalence and direct and indirect costs. ${ }^{5}$ Moreover, the burden associated with these psychiatric disorders includes a broad range of negative aspects, from personal interrelationship problems to productivity loss at work, which substantially impair the patients' HRQOL. ${ }^{6}$ Several studies have demonstrated the association between psychiatric disorders and social, environmental, and psychological aspects of quality of life, with an effect size comparable to other serious clinical conditions such as cancer and coronary artery disease. ${ }^{7,8}$

Therefore, the objective of this study was to evaluate the association between sociodemographic and clinical variables, including anxiety and depressive symptoms, and the HRQOL of a Brazilian sample of patients followed up in a tertiary outpatient clinic for depression and anxiety disorders.

\section{Methods}

\section{Study design and sample}

In this cross-sectional study, patients were followed up in a tertiary outpatient clinic for depression and anxiety disorders at the University Hospital of the Universidade Federal de Santa Catarina, which serves the metropolitan area of Florianópolis (approximately 800,000 habitants) in the state of Santa Catarina, Brazil.

Inclusion criterion was patients aged 18 years or older. Exclusion criteria were intellectual disability diagnosed by clinical evaluation and other health conditions that could prevent the participants from understanding the objectives of the study and completing the protocol, such as hearing impairment. The study was approved by the Human Research Ethics Committee of the Universidade Federal de Santa Catarina. Written informed consent was obtained from all patients.

\section{Measures}

Sociodemographic and clinical data included gender, age, marital status, educational level, religion, per capita household income, health insurance coverage, duration of the primary psychiatric disorder, and presence of nonpsychiatric comorbidity. The presence of a non-psychiatric comorbidity was established when the patient reported any medical condition diagnosed by a medical doctor that could interfere with his or her quality of life as assessed by the authors. We considered the following conditions: diabetes mellitus, cardiomyopathy, thyroid disease, bone/muscle diseases, epilepsy, and immunodeficiency syndromes. Educational level was classified into three categories: higher, secondary, and primary education. Religion was categorized into practitioner, non-practitioner, and without religion.

Psychometric test: the Hospital Anxiety and Depression Scale (HADS) is a valid tool for measuring depression and anxiety symptoms in individuals with mental disorders and comorbidity with other clinical conditions. ${ }^{9}$ This tool was validated for the Brazilian population. ${ }^{10}$ Because of the well-documented high comorbidity between depression and anxiety symptoms, ${ }^{11}$ we used HADS total scores instead of its subscales separately.

Quality of life assessment: the short version of the World Health Organization Quality of Life (WHOQOLBREF) was used for HRQOL evaluation. ${ }^{12}$ This scale comprises 26 items that provide a total score in addition to scores for five subdomains: overall quality of life and general health, physical health, psychological health, social relationships, and environment. The WHOQOLBREF was validated for Brazilian outpatients with depression. ${ }^{13}$ Higher scores indicate better quality of life.

Because most participants of our study had low educational level, all assessment tools were administered by an interviewer.

\section{Statistical analysis}

A series of simple linear regression analyses were conducted to determine the variables associated with the total scores of the WHOQOL-BREF and each of its subdomains (overall quality of life and general health, physical health, psychological health, social relationships, and environment). The independent variables were gender, age, duration of the psychiatric disorder, educational level, marital status, employment status, 
health insurance coverage, HADS score, religion, presence of non-psychiatric disease, and per capita household income. Thereafter, we performed a multiple linear regression analysis including only the variables associated with the outcome with a level of statistical significance less than 0.20 in the simple linear regression analysis. Collinearity between the predictor variables was assessed based on the condition index (threshold of 30). In the final model of the multiple linear regression analysis, $p<$ 0.05 was considered statistically significant. The normal distribution of the standardized residuals was analyzed to verify the extent to which the model fit the data. The statistical analyses were performed using the Statistical Package for the Social Sciences (SPSS) version 17.0.

\section{Results}

Of the 80 eligible patients, 75 agreed to participate (93\%) and were evaluated from May 2013 to June 2014. Their sociodemographic and clinical characteristics are presented in Table 1 . Most participants were female $(70.7 \%)$, their mean age was 40.7 ( \pm 13.1 SD) years old, and the mean duration of their psychiatric disorder was 14.3 ( \pm 12 SD) years. Only $17.3 \%$ had higher education, and approximately half of the sample was married. Most of the sample was employed, and $70 \%$ of those unemployed had health insurance coverage. One-third of the participants reported at least one nonpsychiatric comorbidity (Table 1 ).

Table 1 - Sociodemographic, clinical, and quality of life characteristics of 75 patients followed up in a tertiary psychiatric outpatient clinic

\begin{tabular}{|c|c|}
\hline Variables & All patients \\
\hline \multicolumn{2}{|l|}{ Gender } \\
\hline Female & $53(70.7)$ \\
\hline Male & $22(29.3)$ \\
\hline Age at evaluation (years) & $40.7 \pm 13.1$ \\
\hline Duration of the psychiatric disorder (years) & $14.3 \pm 12.0$ \\
\hline \multicolumn{2}{|l|}{ Educational level } \\
\hline Higher & $13(17.3)$ \\
\hline Secondary & $36(48)$ \\
\hline Primary & $26(34.7)$ \\
\hline \multicolumn{2}{|l|}{ Married } \\
\hline Yes & $36(48.6)$ \\
\hline No & $38(51.4)$ \\
\hline \multicolumn{2}{|l|}{ Employed } \\
\hline Yes & $44(58.7)$ \\
\hline No & $31(41.3)$ \\
\hline \multicolumn{2}{|l|}{ Health insurance coverage* } \\
\hline Yes & $24(32.4)$ \\
\hline No & $50(67.6)$ \\
\hline \multicolumn{2}{|l|}{ Religion } \\
\hline Yes/practitioner & $45(60)$ \\
\hline Yes/non-practitioner & $20(26.7)$ \\
\hline No & $10(13.3)$ \\
\hline HADS & $20.2 \pm 9$ \\
\hline \multicolumn{2}{|l|}{ Diagnosis of non-psychiatric disorder ${ }^{+}$} \\
\hline No & $49(65.3)$ \\
\hline Yes & $26(34.7)$ \\
\hline Per capita household income, ${ }^{\ddagger}$ median (IQR) & $5045(3375-8182)$ \\
\hline WHOQOL-BREF physical health & $48.4 \pm 20.2$ \\
\hline WHOQOL-BREF psychological health* & $45.4 \pm 21.1$ \\
\hline WHOQOL-BREF social relationships & $49 \pm 21.8$ \\
\hline WHOQOL-BREF environment & $53.6 \pm 14.8$ \\
\hline WHOQOL-BREF overall quality of life/general health & $49 \pm 21$ \\
\hline WHOQOL-BREF total scores* & $49.2 \pm 16.2$ \\
\hline
\end{tabular}

Data presented as $\mathrm{n}(\%)$ or mean \pm standard deviation, unless otherwise stated.

HADS = Hospital Anxiety and Depression Scale; IQR = interquartile range; WHOQOL-BREF = short version of the World Health Organization Quality of Life scale. * One missing.

+ Cardiopathy, diabetes mellitus, thyroid disorders, bone/muscle diseases, epilepsy, immunodeficiency syndromes.

₹ Annual, in dollars; distribution violated assumptions for parametric testing. 
Based on the cutoff scores for the HADS-A (subscale anxiety) and HADS-D (subscale depression) suggested by a cross-sectional study, ${ }^{14} 76 \%$ and $65 \%$ of our sample would be screened for generalized anxiety disorder and major depression episode, respectively, and $53 \%$ of the sample would be screened positive for both disorders, a percentage similar to that found in the literature. ${ }^{11}$ In addition, $92 \%$ of our sample had at least a mild level of depression and anxiety symptoms at evaluation. After the analysis of collinearity, the variable health insurance coverage was removed from the final model of the WHOQOL-BREF total scores, physical, psychological, social, and environment subdomains.

\section{WHOQOL-BREF total scores}

The predictor variables gender, age, educational level, employment status, health insurance coverage, HADS score, and religion were associated with the WHOQOL-BREF total score in the simple linear regression. In addition to these variables, duration of psychiatric disorder, non-psychiatric comorbidity, and per capita household income had a trend for association (Table 2) and were included in the multiple linear regression analysis. In the final model, female gender and higher HADS scores were independently associated with poor WHOQOL-BREF total scores. The model explained $70 \%$ of the variability of the outcome (Table 3 ).

Table 2 - Variables associated with the short version of the World Health Organization Quality of Life (WHOQOL-BREF) total score domain

\begin{tabular}{|c|c|c|c|c|}
\hline Predictive variables & $\mathbf{R}$ & $\mathbf{R}^{\mathbf{2}}$ & B coefficient & $\mathbf{p}$ \\
\hline Gender & 0.40 & 0.16 & -14.3 & 0.000 \\
\hline Age at evaluation & 0.37 & 0.14 & -0.45 & 0.001 \\
\hline Duration of the psychiatric disorder & 0.22 & 0.05 & -0.30 & 0.06 \\
\hline Educational level & 0.45 & 0.20 & -10.3 & 0.000 \\
\hline Marital status & 0.15 & 0.02 & 4.8 & 0.21 \\
\hline Employment & 0.50 & 0.25 & -16.29 & 0.000 \\
\hline Health insurance coverage & 0.41 & 0.17 & 13.8 & 0.000 \\
\hline Hospital Anxiety and Depression Scale (HADS) scores & 0.81 & 0.66 & -1.46 & 0.000 \\
\hline Religion & 0.31 & 0.10 & 7 & 0.006 \\
\hline Diagnosis of non-psychiatric disorder & 0.19 & 0.03 & -6.33 & 0.11 \\
\hline Per capita household income & 0.20 & 0.04 & 0.001 & 0.10 \\
\hline
\end{tabular}

Table 3 - Predictive model showing the variables independently associated with the short version of the World Health Organization Quality of Life (WHOQOL-BREF) total score domain

\begin{tabular}{lc}
\hline Predictive variables & B coefficient (95\%CI) \\
\hline Gender & $-6.25(-11.13$ to -1.37$)$ \\
Hospital Anxiety and Depression Scale (HADS) total scores & $-1.18(-1.47$ to -0.90$)$ \\
\hline
\end{tabular}

$95 \% \mathrm{CI}=95 \%$ confidence interval.

$R=0.86 ; R^{2}=0.70 ; F=20.06 ; p=0.000$.

\section{WHOQOL-BREF general health domain}

After simple linear regression (data not shown), all variables, except marital status, diagnosis of nonpsychiatric disorder, and religion, were included in the final model. After the multiple linear regression analysis, only the HADS scores were independently associated with poor general health. The model explained $40 \%$ of the variability of the outcome $(p<0.000)$ (Table 4).

Table 4 - Multiple linear regressions showing the variables independently associated with the short version of the World Health Organization Quality of Life (WHOQOL-BREF) domains

\begin{tabular}{|c|c|c|c|c|c|c|c|c|c|c|}
\hline \multirow[t]{2}{*}{ Domains } & \multicolumn{2}{|l|}{ Physical } & \multicolumn{2}{|l|}{ Psychological } & \multicolumn{2}{|l|}{ Social } & \multicolumn{2}{|l|}{ Environment } & \multicolumn{2}{|c|}{ Overall QoL } \\
\hline & $\begin{array}{c}\text { B coefficient } \\
(95 \% \mathrm{CI})\end{array}$ & $\mathbf{p}$ & $\begin{array}{c}\text { B coefficient } \\
(95 \% \mathrm{CI})\end{array}$ & $\mathbf{p}$ & $\begin{array}{c}\text { B coefficient } \\
(95 \% \mathrm{CI})\end{array}$ & $\mathbf{p}$ & $\begin{array}{c}\text { B coefficient } \\
(95 \% \mathrm{CI})\end{array}$ & $\mathbf{p}$ & $\begin{array}{c}\text { B coefficient } \\
(95 \% \mathrm{CI})\end{array}$ & $\mathbf{p}$ \\
\hline Gender & NS & - & $\begin{array}{c}-7.46 \\
(-14.45 \text { to }-0.47)\end{array}$ & 0.04 & NS & - & $\begin{array}{c}-8.30 \\
(-14.04 \text { to }-2.56)\end{array}$ & 0.005 & NS & \\
\hline $\begin{array}{l}\text { HADS total } \\
\text { scores }\end{array}$ & $\begin{array}{c}-1.38 \\
(-1.77 \text { to }-0.99)\end{array}$ & 0.000 & $\begin{array}{c}-1.56 \\
(-1.97 \text { to }-1.15)\end{array}$ & 0.000 & NS* & - & $\begin{array}{c}-0.92 \\
(-1.27 \text { to }-0.58)\end{array}$ & 0.000 & $\begin{array}{c}-1.29 \\
(-1.79 \text { to }-0.78)\end{array}$ & 0.000 \\
\hline \multirow[t]{2}{*}{ Employment } & $\begin{array}{c}-9.05 \\
(-16.26 \text { to }-1.84)\end{array}$ & 0.01 & NS & - & NS & - & NS & - & NS & \\
\hline & $\begin{aligned} \mathrm{R} & =0.84 ; \mathrm{R}^{2}= \\
\mathrm{F} & =15.3 ; \mathrm{p}=0\end{aligned}$ & $\begin{array}{l}0.66 \\
0.000\end{array}$ & $\begin{array}{l}\mathrm{R}=0.82 ; \mathrm{R}^{2}=0 \\
\mathrm{~F}=16.84 ; \mathrm{p}=0\end{array}$ & $\begin{array}{l}0.64 ; \\
0.000\end{array}$ & $\begin{aligned} \mathrm{R} & =0.52 ; \mathrm{R}^{2}= \\
\mathrm{F} & =3.06 ; \mathrm{p}=\end{aligned}$ & $\begin{array}{l}18 ; \\
005\end{array}$ & $\begin{aligned} \mathrm{R} & =0.74 ; \mathrm{R}^{2}=0 \\
\mathrm{~F} & =9.92 ; \mathrm{p}=0\end{aligned}$ & $\begin{array}{l}0.50 ; \\
0.000\end{array}$ & $\begin{array}{l}\mathrm{R}=0.67 ; \mathrm{R}^{2}= \\
\mathrm{F}=7.8 ; \mathrm{p}=0\end{array}$ & $\begin{array}{l}0.40 \\
.000\end{array}$ \\
\hline
\end{tabular}

$95 \% \mathrm{CI}=95 \%$ confidence interval; HADS = Hospital Anxiety and Depression Scale; NS = non-significant; QoL = quality of life.

* Trend for association $(\mathrm{p}=0.08)$. 


\section{WHOQOL-BREF physical domain}

After simple linear regression (data not shown), all variables were included in the final model. After multiple linear regression analysis, only higher HADS scores and unemployment were independently associated with poor physical scores. The model explained $66 \%$ of the variability of the outcome $(p<0.000)$ (Table 4$)$.

\section{WHOQOL-BREF psychological domain}

After simple linear regression (data not shown), all variables, except psychiatric disorder and marital status, were included in the final model. After multiple linear regression analysis, only female gender and higher HADS scores were independently associated with poor psychological scores. The model explained $64 \%$ of the variability of the outcome $(p<0.000)$ (Table 4$)$.

\section{WHOQOL-BREF SOcial domain}

After simple linear regression (data not shown), all variables, except marital status and per capita household income, were included in the final model. After multiple linear regression analysis, only higher HADS scores had a trend for association with poor social scores in the final model $(p=0.08)$ (Table 4$)$.

\section{WHOQOL-BREF environment domain}

After simple linear regression (data not shown), all variables, except duration of the psychiatric disorder and diagnosis of a non-psychiatric disorder, were included in the final model. After multiple linear regression analysis, only female gender and higher HADS scores were independently associated with poor environment scores. The model explained $50 \%$ of the variability of the outcome $(p<0.000)$ (Table 4$)$.

Residuals from all multiple linear regression analyses had a normal distribution (data not shown).

The total time required for the administration of the assessment tool was approximately one hour.

\section{Discussion}

Considering the sociodemographic and clinical variables analyzed, our findings demonstrated that only gender, depression and anxiety symptoms, and employment status were independently associated with one or more HRQOL domains in the final models of multiple linear regressions. Female gender was independently associated with poor HRQOL for all domains, except physical health, social relationships, and overall quality of life and general health. Unemployment was associated only with physical health according to the multiple linear regression analysis. The HADS scores were independently associated with all HRQOL domains, except social relationships, which had a trend for association.

In disagreement with our results, marital status is commonly associated with HRQOL in the literature. Daly et al. found an association between unmarried patients and poor HRQOL even after adjusting for age and severity of depressive symptoms. ${ }^{15}$ Similar results were found by Nyer et al. These authors found that, in addition to the association with better quality of life, marriage conferred protection against suicidal ideation in patients with schizophrenia and depressive symptoms. ${ }^{16}$ Stroppa \& Moreira-Almeida found an association between religiosity and fewer depressive symptoms and improved quality of life in patients with bipolar disorder. ${ }^{17}$ Despite the association between religion and most HRQOL domains in the linear regression analysis, this association was not present in any of our multiple linear analyses.

Female gender and older age were associated with lower HRQOL scores in community surveys not considering psychiatric symptoms. ${ }^{18,19}$ Galvão et al. found an association between psychiatric disorders evaluated by the Self-Reporting Questionnaire (SRQ$20)^{20}$ and worse Medical Outcomes Study 36-item Short-Form Health Survey (SF-36) scores $^{21}$ in women with low level of education, low family income, and in unemployed women. However, the analysis did not adjust for confounders, making it difficult to exclude interactions between the predictors. ${ }^{22}$

Similarly to our results, in a study with 1,466 patients from Brazilian primary health care units evaluated using the WHOQOL-BREF, the HADS, and a sociodemographic questionnaire, Portugal et al. found an association between higher depression and anxiety symptoms and lower quality of life, particularly in females older than 40 years of age. Nevertheless, the authors also did not adjust for possible confounders. ${ }^{23}$

In our study, depression and anxiety symptoms measured by HADS scores were associated with all WHOQOL domains in the multiple linear regressions, except for social relationships, which had a trend for association. This independent association could be found for all WHOQOL domains with a larger sample size. These results are in agreement with the study by D'Avanzato et al., in which the authors found an association between levels of anxiety and worse HRQOL scores in all domains. Furthermore, they reported a correlation between anxiety symptoms 
and higher scores of dissatisfaction with mental and physical health, in addition to impairment in leisure and friendship activities. ${ }^{24}$

The negative association between quality of life and anxiety and depression symptoms measured by the HADS was also found in the study by Brett et al. in a population of 1,641 elderly persons in a linear regression analysis. ${ }^{18}$ Depression increases the feeling of functional disability, impairs the quality of social relationships and treatment adherence, and contributes to substantial impairment in the patient's quality of life. ${ }^{25,26}$ Our results reinforced that, in a Brazilian sample from a tertiary outpatient clinic, psychiatric symptoms, especially depression, have a negative impact on patients, even considering any variable or medical disease. ${ }^{27,28}$

Our study has some limitations. The cross-sectional design did not allow us to infer a causal relationship between poor quality of life and psychiatric disorders. Additionally, our sample was from a tertiary outpatient clinic; thus limiting the generalization of the results for patients with less severe symptoms. Also, information on physical activity, which is an important predictor of quality of life, ${ }^{29,30}$ was not collected.

\section{Conclusion}

Depression and anxiety symptoms were independently associated with all HRQOL domains in our study, except social relationships, which had a trend for association. HRQOL has received substantial attention in medical research and has been used as the primary outcome in clinical trials, with the reduction of clinical symptoms becoming a secondary outcome.3,31 Therefore, identifying the factors associated with $\mathrm{HRQOL}$ and recognizing that depression and anxiety are major factors is essential to improve the care of patients.

\section{Acknowledgements}

The authors thank the staff of the University Hospital of the Universidade Federal de Santa Catarina for their kind cooperation during the study.

\section{References}

1. Strawbridge WJ. Quality of life: what is it and can it be measured? Growth Horm IGF Res. 1998;8:59-62.

2. Berlim MT, Fleck MP. "Quality of life": a brand new concept for research and practice in psychiatry. Rev Bras Psiquiatr. 2003;25:249-52.
3. Schuepbach WM, Rau J, Knudsen K, Volkmann J, Krack P, Timmermann $L$, et al. Neurostimulation for Parkinson's disease with early motor complications. N Engl J Med. 2013;368:610-22.

4. Mendlowicz MV, Stein MB. Quality of life in individuals with anxiety disorders. Am J Psychiatry. 2000;157:669-82.

5. Gustavsson A, Svensson M, Jacobi F, Allgulander C, Alonso J, Beghi $E$, et al. Cost of disorders of the brain in Europe 2010. Eur Neuropsychopharmacol. 2011;21:718-79.

6 . Rocha NS, Fleck MP. Evaluation of quality of life in adults with chronic health conditions: the role of depressive symptoms. Rev Bras Psiquiatr. 2010;32:119-24.

7. Cretu RZ, David AM. Comparative study: the quality of life of patients with leukemia, anxiety and depressive disorders. Procedia Soc Behav Sci. 2014;127:883-6.

8. Fleck $M P$, Lima $A F$, Louzada $S$, Schestasky $G$, Henriques $A$ Borges VR, et al. [Association of depressive symptoms and social functioning in primary care service, Brazil]. Rev Saude Publica. 2002;36:431-8.

9. Zigmond AS, Snaith RP. The hospital anxiety and depression scale. Acta Psychiatr Scand. 1983;67:361-70.

10. Botega NJ, Bio MR, Zomignani MA, Garcia C Jr, Pereira WA [Mood disorders among inpatients in ambulatory and validation of the anxiety and depression scale HAD]. Rev Saude Publica. 1995;29:355-63.

11. Kessler RC, Sampson NA, Berglund P, Gruber MJ, Al-Hamzaw $A$, Andrade $L$, et al. Anxious and non-anxious major depressive disorder in the World Health Organization World Mental Health Surveys. Epidemiol Psychiatr Sci. 2015;27:1-17.

12. Skevington SM, Lotfy M, O'Connell KA; WHOQOL Group. The World Health Organization's WHOQOL-BREF quality of life assessment: psychometric properties and results of the international field trial. A report from the WHOQOL group. Qual Life Res. 2004;13:299-310.

13. Berlim MT, Pavanello DP, Caldieraro MA, Fleck MP. Reliability and validity of the WHOQOL BREF in a sample of Brazilian outpatients with major depression. Qual Life Res. 2005;14:561-4.

14. Olsson I, Mykletun A, Dahl AA. The Hospital Anxiety and Depression Rating Scale: a cross-sectional study of psychometrics and case finding abilities in general practice. BMC Psychiatry. 2005;5:46.

15. Daly EJ, Trivedi MH, Wisniewski SR, Nierenberg AA, Gaynes BN, Warden $D$, et al. Health-related quality of life in depression: a STAR*D report. Ann Clin Psychiatry. 2010;22:43-55.

16. Nyer M, Kasckow J, Fellows I, Lawrence EC, Golshan S, Solorzano $E$, et al. The relationship of marital status and clinical characteristics in middle-aged and older patients with schizophrenia and depressive symptoms. Ann Clin Psychiatry. 2010;22:172-9.

17. Stroppa A, Moreira-Almeida A. Religiosity, mood symptoms, and quality of life in bipolar disorder. Bipolar Disord. 2013;15:385-93.

18. Brett CE, Gow AJ, Corley J, Pattie A, Starr JM, Deary IJ. Psychosocial factors and health as determinants of quality of life in community-dwelling older adults. Qual Life Res. 2012;21:505-16

19. Al-Fayez GA, Ohaeri JU. Profile of subjective quality of life and its correlates in a nation-wide sample of high school students in an Arab setting using the WHOQOL-Bref. BMC Psychiatry. 2011;11:71

20. Iacoponi E, Mari JJ. Reliability and factor structure of the Portuguese version of Self-Reporting Questionnaire. Int J Soc Psychiatry. 1989;35:213-22.

21. Ware JE Jr, Sherbourne CD. The MOS 36-item short-form health survey (SF-36). I. Conceptual framework and item selection. Med Care. 1992;30:473-83.

22. Galvao LL, Farias MC, de Azevedo PR, Vilar MJ, de Azevedo GD. [Prevalence of mental disorders and assessment of quality of life in the climaterium]. Rev Assoc Med Bras. 2007;53:414-20.

23. Portugal FB, Campos MR, Gonçalves DA, Mari JJ, Gask L, Bower $P$, et al. Psychiatric morbidity and quality of life of primary care attenders in two cities in Brazil. J Bras Psiquiatr. 2014;63:23-32.

24. D'Avanzato C, Martinez J, Attiullah N, Friedman M, Toba C, Boerescu DA, et al. Anxiety symptoms among remitted depressed outpatients: prevalence and association with quality of life and psychosocial functioning. J Affect Disord. 2013;151:401-4.

25. Berber JS, Kupek E, Berber SC. Prevalência de depressão e sua relação com a qualidade de vida em pacientes com síndrome da fibromialgia. Rev Bras Reumatol. 2005;45:47-54.

26. Jansen K, Mondin TC, Ores Lda C, Souza LD, Konradt CE, Pinheiro RT, et al. [Mental common disorders and quality 
of life in young adulthoods: a population-based sample in Pelotas, Rio Grande do Sul State, Brazil]. Cad Saude Publica. 2011;27:440-8.

27. Mental health: the great depression. Nature. 2014;515:179.

28. The burden of depression. Nature. 2014;515:163.

29. Pucci G, Reis RS, Rech CR, Hallal PC. Quality of life and physical activity among adults: population-based study in Brazilian adults. Qual Life Res. 2012;21:1537-43.

30. Omorou YA, Erpelding ML, Escalon $\mathrm{H}$, Vuillemin A. Contribution of taking part in sport to the association between physical activity and quality of life. Qual Life Res. 2013;22:2021-9.

31. Ardeshna KM, Qian W, Smith P, Braganca N, Lowry L, Patrick P, et al. Rituximab versus a watch-and-wait approach in patients with advanced-stage, asymptomatic, non-bulky follicular lymphoma: an open-label randomised phase 3 trial. Lancet Oncol. 2014;15:424-35.

\section{Correspondence:}

Alexandre Paim Diaz

Programa de Residência Médica em Psiquiatria

Instituto de Psiquiatria de Santa Catarina

88.123-000 - São José, SC - Brazil

Tel.: +55 (48) 3954.2000

Fax: +55 (48) 3954.2011

E-mail: alexandrepaimdiaz@gmail.com 